\title{
A APLICAÇÃo DA CLÁUSUlA DE TERRITORIALIDADE NO CONTRATO DE FRANQUIA SOB A ÓTICA CONCORRENCIAL
}

\author{
THE APPLICATION OF TERRITORIALITY CLAUSE IN FRANCHISE \\ AGREEMENT UNDER ANTITRUST PERSPECTIVE
}

${ }^{1}$ Leonardo Da Silva Sant Anna
${ }^{2}$ Leticia Lobato Anicet Lisboa

\section{RESUMO}

O presente artigo tem como objetivo analisar se a cláusula de territorialidade do contrato de franquia trata-se de prática que viola o princípio da livre iniciativa e da livre concorrência. À vista disto, será apresentado o conceito de franquia empresarial à luz da Lei $n^{\circ} 8.955$ de 1994, ressaltando a relevância econômico-social do sistema e a necessidade de edição de normas que versem sobre as lacunas da Lei. O método utilizado para o trabalho foi o dedutivo, a pesquisa realizada foi de caráter documental e envolveu a análise de legislação, além de estudos doutrinários, jurisprudenciais, e exame de artigos em periódicos. A cláusula de territorialidade foi analisada com enfoque comercial, destacando sua importância para a formalização do contrato de franquia. Observou-se que a falta de posicionamento claro dos Tribunais Superiores e do CADE a respeito da cláusula de territorialidade nos contratos de franquia, prejudica a análise sob a ótica do direito concorrencial. Apenas quando estes órgãos se manifestarem diretamente sobre a referida cláusula, poder-se-á esclarecer definitivamente a questão.

Palavras-chave: Franquia, Contrato, Territorialidade, Exclusividade, Direito concorrencial

\begin{abstract}
The purpose of this article is to analyze if the territoriality clause in franchise agreement is a practice which violates the principle of free enterprise and competition. Therefore, it will be presented the concept of franchising according to Law $\mathrm{n}^{\circ} 8.955$ of 1994, highlighting its economical and social importance and the need of issuing rules which deal with gaps of the Law. The method applied in this study was deductive, the research conducted was based on documents, and involved the analysis of legislations, doctrinal and jurisprudential studies, as well as review of journal articles. The territoriality clause was analyzed with commercial focus, emphasizing its relevance to franchise agreement conclusion. It was noted that the lack of clear positioning of the Superior Courts and CADE regarding the territoriality clauses in franchise agreements, affect the analysis under perspective of antitrust law. Only when those authorities pronounce directly about this subject, the issue may finally be clarified.
\end{abstract}

Keywords: Franchising, Agreement, Territoriality, Exclusivity, Antitrust law

1Doutor em Saúde Pública pela Fundação Oswaldo Cruz -FIOCRUZ, São Paulo, (Brasil). Professor do Programa de Pós-Graduação em Direito (PPGDIR) e da Graduação do Direito pela Universidade do Estado do Rio de Janeiro - UERJ. E-mail: 1santanna44@gmail.com

2 Mestranda em Direito pela Universidade do Estado do Rio de Janeiro - UERJ, Brasil. E-mail: leticialalisboa@yahoo.com.br 


\section{INTRODUÇÃO}

A franquia empresarial trata-se de um sistema de distribuição de produtos ou serviços em que os direitos de uso de marca e tecnologia de uma sociedade empresária, denominada franqueadora são cedidos contratualmente a terceiros, franqueadores, mediante certas contraprestações, quais sejam royalties pelo uso da marca e remuneração pelos serviços adquiridos, conforme a previsão contratual.

O sistema de franquia surge no século XIX, na economia norte-americana, como prática comercial amplamente utilizada por comerciantes que criavam redes de distribuição com objetivo de expandir seus negócios, sendo certo que tal prática passa a ter seu crescimento acentuado após a segunda guerra mundial.

Por conseguinte, a franchising passa a ser adotado mundialmente como estratégia comercial para expansão das sociedades empresárias. Portanto, a Lei nº 8.955 de 15 de dezembro de 1994 é editada com intuito de tipificar o contrato de franquia, e, estabelecer os requisitos de validade específicos desta relação contratual.

O contrato de franquia é um mecanismo eficaz de comercialização de produtos, mercadorias e serviços, gerando ao franqueador a ampliação de seu negócio por meio de redes de distribuição, aumentando o faturamento empresarial. Em contrapartida, proporciona ao franqueado uma forma mais célere de constituir um negócio próprio, sob resguardo de uma marca de sucesso.

Este sistema é considerado uma opção bastante vantajosa de investimento, tendo em vista que o franqueado investirá seu capital em uma sociedade cuja marca tem reconhecida credibilidade perante o consumidor, reduzindo as possibilidades de fracasso do negócio.

O contrato de franquia, é no Brasil, regulado pela Lei ${ }^{\circ} 8.955$ de 1994, conhecida como Lei de Franquias (LF), pressupõe a exclusividade ou semi-exclusividade do franqueado no território estabelecido contratualmente, previamente informado na circular de oferta de franquia.

Contudo, tal cláusula que veda o estabelecimento do franqueado em local diverso do estipulado contratualmente, muitas vezes trata-se de decisão unilateral do franqueador, o que gera questionamentos do franqueado e de terceiros a respeito de sua livre iniciativa, e independência de seu negócio.

Diante da cláusula de territorialidade, o franqueado fica impedido de expandir seus 
negócios, e deve apenas vender seus produtos ou prestar serviços de forma limitada, restrito a uma localidade, e clientela específica.

Não obstante, a cláusula de exclusividade territorial, atualmente, traz questionamentos a respeito de seu abuso econômico, considerando que grande parcela de consumidores utiliza métodos externos como fonte primária para aquisição de produtos e serviços, tais como as compras virtuais, o que poderia significar uma restrição aos negócios do franqueado.

Deste modo, o objetivo geral do presente trabalho é definir, com supedâneo na legislação civil, doutrina e jurisprudência dos Tribunais Superiores e do Conselho Administrativo de Defesa Econômica (CADE), se a restrição territorial consolidada no contrato de franquia é válida, considerando o direito concorrencial.

O método utilizado para o trabalho foi o dedutivo, a pesquisa realizada foi de caráter documental e envolveu a análise de legislação, além de estudos doutrinários, jurisprudenciais, e exame de artigos em periódicos.

O primeiro capítulo tem como objetivo específico a conceituação do contrato de franquia, através de seu histórico e análise da LF, que conforme será analisada a seguir não é suficiente para regular a relação entre franqueado e franqueador.

Por conseguinte, o segundo capítulo analisará a cláusula de territorialidade, sua importância e implicações comerciais.

O terceiro capítulo tratará da perspectiva concorrencial a respeito da cláusula de territorialidade, e para tanto, serão analisados julgados do CADE sobre a cláusula de territorialidade nos contratos de locação em shopping centers, bem como acerca da configuração de prática antitruste dos contratos de franquias, para ao final concluir se a cláusula de territorialidade nos contratos de franquias corresponde ou não a uma conduta anticoncorrencial.

\section{DO CONTRATO DE FRANQUIA À LUZ DA LEI No 8.955 DE 1994}

O sistema de franquia tem origem na idade média $^{1}$, dos anos de 400 a 1500 antes de Cristo. Era uma prática comum os governantes locais oferecerem às pessoas importantes e até mesmo aos oficiais de alto cargo da igreja, uma licença concedendo-lhes o direito de manter a 
ordem cívica e fazer recolhimentos de impostos. Os tribunais ou lordes podiam, ainda, conceder direitos a terceiros para operar balsas, manter mercados e realizar atividades relativas a negócios que hoje são exercidos por profissionais e corporações.

Luiz Felizardo Barroso $^{2}$ por outro lado afirma que a Franquia empresarial surgiu, primordialmente, nas expedições marítimas europeias. Naquele tempo, os navegadores procuravam novas terras em nome dos monarcas, para expansão dos negócios destes e aquisição de riquezas.

O primeiro caso de sucesso das franquias empresariais, ocorre em 1860 quando a Singer Sewing Machine Company ${ }^{3}$, pretendendo ampliar sua participação no mercado varejista, outorgou franquias a pequenos comerciantes, que então passaram a comercializar seus produtos em lojas “Singer”, arcando com suas próprias despesas e riscos.

O sistema adotado pela Singer Sewing Machine Company se destacou pelo sucesso nacional da sociedade, tendo em vista a publicidade aplicada à rede, técnica para vendas no varejo e transferência de know-how para os franqueados que cuidavam pessoalmente de seus negócios.

Na última década do século XIX, a General Motors e a Coca-Cola utilizaram do modelo de negócios implantado pela Singer, sendo que a primeira deu início às chamadas concessionárias de veículos, no intuito de expandir sua rede de revenda de automóveis, enquanto a segunda optou por franquear a terceiros não apenas o uso de sua marca, mas a própria produção e envasamento de seu produto como estratégia de mercado para melhor distribuição.

Com o sucesso do sistema nos Estados Unidos, o denominado franchise boom, a franquia se espalhou por todo o mundo, uma vez que o crescimento populacional associado à ampliação geográfica dos mercados consumidores gerou a necessidade de criação de métodos

\footnotetext{
1 HOLLOWELL, Ken. The History of Franchising. Artigo disponível em <http://www.evancarmichael.com/Franchises/666/THE-HISTORY-OF-FRANCHISING.html>. Acesso em 28 de maio de 2015.

${ }^{2}$ BARROSO, Luiz Felizardo. Franchising e Direito. Rio de Janeiro. Lumen Juris. 2002, p. 13.

${ }^{3}$ DINIZ, Maria Helena. Tratado teórico e prático dos Contratos. São Paulo. Editora Saraiva. 2003, p. 47.
} 
de escoamento de mercadorias mais eficientes e menos oneroso, conforme enuncia Alberto Lopes da Rosa ${ }^{4}$ :

Assim, a antiga forma de distribuição de mercadorias, na qual o produtor se ocupava tanto da produção quanto da distribuição de mercadorias, revelavase cada vez mais custosa e ineficiente, o que indicava a latente necessidade de verificar novas formas de distribuição de mercadorias.

Neste diapasão, foi possível observar, em um país com dimensões continentais como os Estados Unidos, o movimento de grandes companhias que na busca por soluções para distribuição de seus produtos no vasto território norte-americano, desenvolveram o embrião de um sistemal que hoje denominamos franquia empresarial. No Brasil, o sistema de franquia vem sendo utilizado, há décadas, como estratégia mercadológica para distribuição de produtos, baseada na licença de marca a ser explorada por terceiros e pagamento de contraprestações pelos franqueados.

A expansão do franchising no Brasil se iniciou com sociedades estrangeiras que procuraram fincar suas raízes no território nacional de forma desordenada e sem projeto consistentes ao mesmo tempo em que o país passava por sérios problemas econômicos. Neste sentido, reforça Marco Militelli ${ }^{5}$ :

Antes da lei 8.955/94, o franchising no Brasil não dispunha de nenhuma legislação específica para regulamentar a atividade. Por apresentar índices de crescimento anuais muito acima dos índices de crescimento da economia nacional - e também por ser mais seguro do que abrir um negócio por conta própria -, a franchising atraía muitos investidores incautos. Pessoas que, na ansiedade de fazer um bom negócio, deixavam-se levar pela emoção e não analisavam o sistema de direitos e deveres a que seriam submetidas.

Franquia empresarial segundo o artigo $2^{\circ}$ da LF, é o sistema pelo qual um franqueador cede ao franqueado o direito de uso de marca ou patente, associado ao direito de distribuição exclusiva ou semi-exclusiva de produtos ou serviços e, eventualmente, também ao direito de uso de tecnologia de implantação e administração de negócio ou sistema operacional desenvolvidos ou detidos pelo franqueador, mediante remuneração direta ou indireta, sem que, no entanto, fique caracterizado o vínculo empregatício. Nesse sentido corrobora o entendimento de Fran Martins ${ }^{6}$ :

\footnotetext{
${ }^{4}$ ROSA, Alberto Lopes da. A evolução do contrato de franquia empresarial no direito brasileiro e soluções para um desequilíbrio congênito. Disponível em: http://www.publicadireito.com.br/artigos/?cod=f8e59f4b2fe7c570. Acesso em 20 de julho de 2007.

5 MILITELLI, Marco. Obrigações legais da Lei de Franchising 8.955/94. Disponível em <http://www.portaldofranchising.com.br/artigos-sobre-franchising/como-transformar-seu-negocio-emuma- franquia/obrigacoes-legais-da-lei-de-franchising-895594>. Acesso em 20 de julho de 2015.

${ }^{6}$ MARTINS. Fran. Curso de Direito Comercial. 37a Edição. Rio de Janeiro. Editora Gen, 2014, p 118.
} 
Uma modalidade especial de negociação é a que se faz utilizando o contrato de franquia (franchising), pelo qual uma empresa concede, mediante condições especiais, a uma outra o direito desta comercializar marcas ou produtos da primeira sem que, contudo, entre franqueado e franqueador haja vínculo de subordinação. "O franqueado, além dos produtos que vai comercializar, receberá do franqueador permanente assistência técnica, inclusive no que se refere à publicidade dos produtos. Para obter a franquia, em regra o franqueado paga ao franqueador uma taxa inicial, obrigando-se, ainda, a pagar-lhe importâncias suplementares consistentes em porcentagens sobre os produtos vendidos. Por seu lado, o franqueador em regra assegura ao franqueado exclusividade em certo território, sendo considerado esse o lugar ou a região (cidade, grupo de cidades, Estado, grupo de Estados) em que o franqueado terá atuação.

A Lei $n^{\circ} 8.955$ de 1994 estabelece que a franquia se trata de um contrato complexo, ou seja, um conjunto de diversos contratos, cuja unicidade tipicamente configura o contrato de franquia. Assim corrobora o entendimento de Fábio Ulhoa Coelho ${ }^{7}$ :

O contrato de franquia (franchising) corresponde a um dos mecanismos mais aprimorados de prestação de tais serviços. Ele resulta da conjugação de dois outros contratos empresariais. De um lado, a licença de uso de marca, e, de outro, a prestação de serviços de organização de empresa.

O franqueado ao implantar seu negócio terá a assistência técnica e o assessoramento pelo franqueador. Por outro lado, o franqueado deverá pagar uma taxa inicial para ingressar na rede, royalties mensais e taxas de publicidade.

Os royalties são taxas cujo valor será definido de comum acordo pelas as partes, que deverão ser pagas pelo franqueado ao franqueador pelo uso da marca, sob suas diversas formas, pela transferência de know-how, assessoramento, e pela concessão de conhecimentos sobre o sistema e metodologia para administração e gerência do negócio. Royalties são como um investimento que os franqueados fazem coletivamente para sustentar a operação da sociedade franqueadora, visando a constante melhoria dos padrões, serviços e produtos da rede.

Neste sentido, a taxa inicial de franquia é o valor inicial pago pelo franqueado pela adesão e ingresso à rede de franquias e que, em termos gerais, recompensa a assistência concedida pelo franqueador para formatação do negócio ao franqueado.

\footnotetext{
${ }^{7}$ COELHO, Fábio Ulhôa. Curso de Direito Comercial. Volume 1. São Paulo. Editora Saraiva. 2012, p. 131.
} 
Por sua vez, a taxa de publicidade é o valor arrecadado e utilizado para investimento na divulgação da marca em campanhas publicitárias, folhetos e assessoria de imprensa, e tem por objetivo constituir o fundo de marketing que será usado para custear o posicionamento da marca junto aos diversos públicos envolvidos: franqueados e demais investidores, consumidores, órgãos de defesa do consumidor e formadores de opinião.

Em alguns casos, a franqueadora administra esse fundo de marketing de forma compartilhada com os franqueados, que se reúnem em associações para discutir interesses comuns e se aproximar do centro de decisões. Esta integração entre franqueadora e franqueado permite o fortalecimento da parceria entre ambos, propiciando comprometimento, ética e respeito à marca.

Frise-se que a relação jurídica estabelecida entre franqueador e franqueado, como enuncia Maria Helena Diniz $^{8}$, não é de emprego, pois não existe vínculo empregatício entre os dois, tampouco existe vínculo entre o franqueador e os empregados do franqueado.

O franqueado é uma sociedade independente, já que seu proprietário opera e administra sua unidade e, como tal, goza de um certo grau de liberdade. Mas não é totalmente independente, pois deve, contratualmente, observar as normas, políticas e padrões que lhe são estabelecidos pelo franqueador. Além disso, deve agir sob a coordenação deste franqueador e deve procurar observar as sugestões e orientações deste.

Vale ressaltar que o grau de autonomia do franqueado costuma variar de uma organização para a outra, mas, em todos os casos, há a imposição pelo franqueador a cada franqueado, de certos padrões a serem observados por este, nem que seja apenas com relação à identidade visual do estabelecimento.

Normalmente as imposições e restrições são relativamente amplas e estão relacionados ao estabelecimento e à gestão do negócio, ou seja, localização do estabelecimento, abrangência geográfica da comercialização dos produtos, layout da fachada do estabelecimento, padronização equipamentos e instalações, merchandising, rotinas operacionais, lista de clientes e de fornecedores, política comercial, plano anual de negócios, padronização do software de gestão, entre outros.

Deste modo, a franquia pressupõe duas sociedades empresárias independentes, que possuam uma relação de parceria, conservando cada uma sua individualidade jurídica,

\footnotetext{
${ }^{8}$ DINIZ, Maria Helena. op. Cit., p. 32.
} 
assumindo cada uma todo o risco de seus respectivos empreendimentos, responsabilizando-se por todas suas despesas de pessoal, e de manutenção do próprio estabelecimento, observadas as obrigações contratuais e de padronização à rede de franquias. Sob esta ótica, enuncia a autora Marcia Pires 9 :

O interesse mútuo pelo crescimento e fortalecimento da marca é, em contrapartida, a sua alma, o valor maior que orienta as relações diárias entre franqueado e franqueador. Ela define suas obrigações e responsabilidades diante do sistema e para o sistema. A operação diária, os planos e ações de curto prazo exigem, expõem e confrontam franqueador e franqueados com situações de negócio, oportunidades e desafios. A ambos cabe a condição de atuar e se estabelecer de forma positiva e bem-sucedida, para si e para a rede. É o interesse, de franqueador e franqueados, pelo crescimento e fortalecimento da Marca que baliza as decisões diárias e dá sustentação e força ao negócio.

Antes da entrada em vigor da Lei no 8.955 de 1994, não existia nenhuma legislação que regulasse o sistema de franquia, o que gerou insegurança jurídica das partes, e impediu que negócios entre grandes sociedades fossem concretizados.

Da mesma forma, pela falta de regulamentação, era comum os franqueados já constituídos, ao se desligarem da rede de franquias, pedirem vultuosas indenizações alegando vícios de consentimento, considerando o poderio dos franqueadores.

Apesar de imperativo o surgimento da LF, considerando o cenário desfavorável desprovido de regras que tipificassem a relação comercial, a referida lei, ainda hoje em pleno vigor, nunca foi suficiente para regular de forma adequada o sistema de franquia no Brasil, especialmente no tocante ao relacionamento entre franqueador e franqueado após a celebração do contrato.

Embora o Código Civil de 2002 tenha cogitado, a princípio, no artigo 1.052 e seguintes, no capítulo IV, Subtítulo II, referentes às sociedades limitadas, não tratou do sistema de franquia empresarial.

A LF foi editada com o objetivo principal de garantir o acesso do franqueado a todas as informações essenciais da franquia, em momento pré-contratual, sendo que o franqueador deveria fornecê-las por escrito através do documento chamado circular de oferta de franquia.

A circular de oferta de franquia estipula as regras do jogo e deve conter de forma

\footnotetext{
9 PIRES, Marcia. Responsabilidades e obrigações entre franqueado e franqueador. Disponível em $<$ http://www.portaldofranchising.com.br/artigos-sobre-franchising/o-que-e-franchising/responsabilidadese- obrigacoes-entre-franqueado-e-franqueador>. Acesso em 20 de julho de 2015.
} 
clara e acessível, todas as informações sobre o negócio, dados do franqueador, inclusive contábeis, informes sobre a rede de franquias, indicação dos demais franqueados e exfranqueados, e condições que serão estipuladas pelo franqueador como local do estabelecimento, área geográfica para comercialização, clientela, valor de todas as taxas, entre outras, além de uma cópia do modelo do contrato de franquia a ser assinado pelo potencial franqueado.

Conforme dispõe Maria Helena Diniz ${ }^{10}$, a circular deve ser entregue ao candidato a franqueado no mínimo dez dias antes da assinatura do contrato de franquia, e, antes do pagamento de qualquer taxa pelo franqueado, sob pena de anulabilidade do Contrato, e eventual devolução de todas as quantias pagas, mais indenizações cabíveis, perdas e danos.

Diante do exposto, a LF, não regula o relacionamento entre as partes após a celebração do contrato, tratando tão somente do momento anterior. Deste modo o contrato de franquia trata-se de um ajuste contratual atípico que não possui uma lei específica que o regule de maneira eficaz.

Cumpre ressaltar que o Projeto de Lei $\mathrm{n}^{\circ}$ 4.319/08, em trâmite desde 2008 no Congresso Nacional, visa alterar a Lei $\mathrm{n}^{\circ} 8.955$ de 1994 para acrescentar um parágrafo único ao artigo $2^{\circ}$, desta forma prevendo a obrigatoriedade de no mínimo doze meses de existência e funcionamento da sociedade franqueadora para iniciar o sistema de franquia.

De acordo com a justificação da proposta, o prazo de 12 (doze) meses trata-se do prazo mínimo para que uma sociedade empresária se estabeleça e demonstre ao público e ao mercado em geral que tem excelência comercial e administrativa suficientes para estabelecer um sistema de franquia.

Contudo, tal Projeto de Lei é insuficiente, pois não supre as lacunas da Lei ${ }^{\circ} 8.955$ de 1994, e está muito distante das reais necessidades de reformulação da LF, considerando que apenas vislumbra um requisito de validade para a constituição de sistemas de franquias pela sociedade franqueadora, não regulando a relação entre as partes após a assinatura do contrato.

${ }^{10}$ DINIZ, Maria Helena. op. Cit., p. 57. 


\section{DA CLÁSULA DE TERRITORIALIDADE}

A cláusula de territorialidade estabelece a obrigatoriedade da comercialização de produtos e serviços pelo franqueado em determinado território, previamente informado pelo franqueador, sendo vedada a livre comercialização em local externo àquele, sob pena de violação do contrato e especialmente da exclusividade territorial dos demais franqueados.

A cláusula de territorialidade é livremente convencionada pelas partes, não sendo obrigatória ao contrato de franquia, apesar de ser regularmente utilizada na formalização deste instrumento.

Neste sentido, o artigo $3^{\circ}$ da LF prevê que a circular de oferta de franquia deve obrigatoriamente informar se em relação ao território, é garantida a sua exclusividade ou preferência, e as condições de atuação, bem como se existe a possibilidade de o franqueado realizar vendas ou prestar serviços fora de seu território, ou realizar exportações. Sob esta ótica, elucida Fábio Ulhoa Coelho ${ }^{11}$ :

O capítulo da Circular acerca das obrigações do franqueador e direitos do franqueado deve referir-se, de início, à cláusula da territorialidade, importantíssimo aspecto do relacionamento entre franqueador e franqueado. Os interessados devem ser informados pela COF se a franquia adota o sistema de exclusividade territorial para os franqueados. Claro que, na hipótese de adoção deste sistema, fica vedada a possibilidade de atuação além dos limites do território contratado, porque isso feriria a exclusividade de outros franqueados. A cláusula de territorialidade pode estabelecer, também, não exatamente a exclusividade, mas a simples preferência do franqueado, por meio de sistemas de compensação interna da rede. Nesse caso, a definição das condições de atuação além dos limites do território de cada franqueado devem ser claramente estabelecidas, para que não se lesem os interesses de nenhum dos integrantes da rede.

Frise-se que qualquer ponto comercial possui uma área de influência que impacta na rentabilidade do mesmo, tendo em vista o fluxo de pessoas, e entorno do estabelecimento. A existência de centros comerciais, universidades, escolas, praças, bancos, ruas e avenidas de grande movimento de pedestres, ou mesmo, impactam no número de consumidores passantes, bem como no perfil do consumidor médio que frequentará o local, como esclarece Marcus Rocca: 


\begin{abstract}
Dentre as diversas variáveis que remetem ao desenvolvimento com sucesso ou fracasso de um negócio, seja ele de qualquer natureza, pode-se citar a localização, que tem papel importante, pois uma vez estabelecida, não é fácil de ser modificada. Qualquer alteração, por mais simples, exige tempo considerável, inclui custos relativamente proibitivos, e ainda assim sujeita a risco que, mediante planejamento adequado e análise criteriosa, será minimizado, mas não inteiramente eliminado. ${ }^{12}$
\end{abstract}

A localização do ponto comercial e sua área de atuação são inerentes ao sucesso de uma sociedade empresária, considerando que é por meio da localização do ponto comercial que o produto se torna mais acessível aos clientes. Portanto, conforme elucida Maria Isabel Triches, a análise estratégica para posicionamento do estabelecimento comercial é imprescindível ao negócio ${ }^{13}$.

A área de atuação da franquia, é aspecto fundamental para a avaliação mercadológica do franqueado, que poderá analisar a partir do território se a franquia tem potencial para gerar lucros, bem como o tempo de retorno dos investimentos iniciais, considerando que o território influencia diretamente no consumo, seja pelo perfil da clientela, seja pelo fluxo de pessoas.

Apesar de a lei estabelecer como informação obrigatória da circular de oferta de franquia, apenas se há garantia de exclusividade ou preferência de atuação no território, e a possibilidade de comercialização externa de produtos e serviços, considerando o princípio da boa-fé objetiva e de transparência das relações contratuais, é evidente que o franqueado deve informar previamente a área de atuação do franqueado, bem como todos os critérios para definição desta área. Conforme enuncia Fábio Ulhôa Coelho' ${ }^{14}$ :

\begin{abstract}
A lei não menciona, especificamente, a obrigação de informar os critérios para a definição da área de atuação (território) de cada franqueado. Isso, contudo, é essencial para a perfeita avaliação das condições de rentabilidade da franquia e do prazo de amortização do capital investido. Assim, do dever genérico de transparência, conclui-se a necessidade de tal informação, podendo se definir na COF, por exemplo, a metodologia a ser empregada em futuras avaliações do potencial de mercado.
\end{abstract}

12 ROCCA, Marcus Eduardo. Os Clusters Comerciais e as preferências dos consumidores paulistanos (DISSERTAÇÃO). São Paulo. Universidade Paulista, 2012, p.10.

13 TRICHES, Maria Isabel; MEURER, Dayci; ANDRADE, Jéssica Teixeira de; TONETE, Vanessa Alves; FOLLMAN, Neimar. Fatores de localização determinantes para o varejo. Anais do Congresso Internacional de Administração, Paraná, 2014. Disponível em: < http://www.admpg.com.br/2014/selecionados.php>. Acesso em 28 de Julho de 2015.

${ }^{14}$ COELHO, Fábio Ulhôa. op. Cit., p. 
Parte da doutrina entende ser a delimitação territorial um benefício ao franqueado, considerando que este obterá uma consolidação comercial neste local, e caso o contrato firmado estabeleça a obrigatoriedade da exclusividade do franqueado neste território, não haverá concorrência na comercialização dos produtos.

Sob esta ótica, cabe ao franqueador avaliar o tamanho do território, a capacidade de consumo dos habitantes, perfil de consumidores, ou das sociedades empresárias que serão abastecidas, para determinar qual serão as praças de atuação de seus franqueados, bem como quantas unidades franqueadas são necessárias para atendimento de determinada praça, sendo certo que tal verificação apenas é possível com análise de demanda.

As análises precárias de demanda, considerando as limitações territoriais no contrato de franquia sem exclusividade, podem gerar danos a ambas as partes no caso concreto, uma vez que duas ou mais unidades franqueadas, que atuem no mesmo território, sem que haja demanda para tal, podem se prejudicar mutuamente, e ao franqueador em relação à margem de vendas, reputação perante demais franqueados, entre outros.

Ressalte-se que atualmente os contratos de franquia, na opinião de parte da doutrina, não chegam a ser discutidos detalhadamente pelas partes, tratando-se em verdade de contratos de adesão a que o franqueado se sujeita para ingressar no sistema, o que corrobora com o entendimento de que são instrumentos de dominação. Sobre esta questão afirma Luiz Felizardo Barroso ${ }^{15}$ :

Já o contrato de franquia é livremente pactuado entre as partes, podendo o franqueador ditar as regras que deverão ser obedecidas pelo franqueado, que a elas aderirá ou não. Se a elas não vier a aderir, não haverá contrato algum.

Pelo exposto, existem muitos questionamentos advindos da exclusividade quanto à delimitação territorial para comercialização de produtos e prestação de serviços, principalmente quanto ao abuso do poder econômico.

15 BARROSO, Luiz Felizardo. Representação comercial x franchising. As vantagens da franquia empresarial In Revista da EMERJ, v. 13, n50, Rio de Janeiro, 2010, p. 261. 


\section{DA VIABILIDADE DA CLÁUSULA DE TERRITORIALIDADE SOB O ASPECTO CONCORRENCIAL}

Considerando os fundamentos discutidos nos dois primeiros capítulos acerca dos fundamentos da franquia empresarial e sobre a importância comercial da cláusula de territorialidade e suas implicações jurídicas, cumpre a este capítulo a análise da viabilidade da cláusula de territorialidade no contrato de franquia sob a ótica concorrencial.

É de fundamental importância salientar que o assunto foi pouco discutido pelos Tribunais Superiores e pelo Conselho Administrativo de Defesa Econômica, sendo necessária a análise da sua viabilidade pela interpretação de casos semelhantes.

O Conselho Administrativo de Defesa Econômica possui o entendimento que a cláusula de territorialidade em contratos de locação em shopping centers, a chamada cláusula de raio, viola não apenas a livre concorrência, mas a livre iniciativa dos locatários, impedindo-os de abrir novos estabelecimentos comerciais em áreas próximas ao shopping center.

Neste sentido, em 16 de outubro de 1997 foi instaurado processo administrativo contra o Condomínio do Shopping Center Iguatemi, para investigação de prática anticoncorrencial relativa às cláusulas de territorialidade impostas aos contratos de locação firmados pelo centro comercial com possíveis locatários lojistas.

As respectivas cláusulas determinavam que as sociedades empresárias locatárias não poderiam ter outros estabelecimentos comerciais dedicados ao mesmo ramo de atividade por ele exercida no condomínio, dentro de um raio de $2.500 \mathrm{~m}$ (dois mil e quinhentos metros), salvo por autorização expressa, conforme parecer da Secretaria de Direito Econômico do $\mathrm{CADE}^{16}$ :

\footnotetext{
Em 16.10.1997, a Procuradoria Geral do CADE protocolou, nesta Secretaria de Direito Econômico, representação contra o Condomínio Shopping Center Iguatemi de São Paulo, pelo fato de que esse shopping estaria impondo a seus locatários cláusulas contratuais restritivas à livre concorrência e à livre iniciativa, expressas no item 5.9 das Normas Gerais das Locações do referido Condomínio, in verbis:
}

16 BRASIL. CONSELHO ADMINISTRATIVO DE DEFESA ECONÔMICA. Processo Administrativo $\mathrm{n}^{\circ}$ 08012.006636/1997-43. 07/04/2005. Parecer da Secretaria de direito econômico. Disponível em < http://www.cade.gov.br/temp/D_D000000281181641.pdf>. Acesso em 31 de julho de 2015. 
“5.9. Os locatários não poderão ter outro estabelecimento (sede ou filial) dedicado ao mesmo ramo de atividade por ele exercida nos respectivos SUP dentro de um raio de $2.500 \mathrm{~m}$ (dois mil e quinhentos metros), contados do centro do terreno do SHOPPING CENTER, salvo autorização expressa da administração (fl.3 dos autos).

Em 21 de dezembro de 1998 foi instaurada nova representação perante o CADE contra o Condomínio do Shopping Center Iguatemi, que se consubstanciou no processo administrativo $\mathrm{n}^{\circ}$ 08012.009991/1998-82, em que a Participações Morro Vermelho Ltda acusou o condomínio de praticar conduta contra a ordem econômica ao inserir nos contratos de locação cláusulas coibindo seus locatários de se instalarem em outro shopping center, localizado nas adjacências ao Shopping Iguatemi.

Em 17 de maio de 2001, a Secretaria de Direito Econômico (SDE) do CADE, emitiu parecer nos autos do processo administrativo $\mathrm{n}^{\mathrm{o}}$ 08012.009991/1998-82 concluindo pela procedência da representação, dado o inegável caráter anticoncorrencial das cláusulas de exclusividade celebradas pelo condomínio, bem como sugeriu o encaminhamento do parecer ao CADE com recomendação de condenação por infração à ordem econômica nos termos do art. 20, I, II e IV, c/c o art. 21, IV e V da Lei $\mathrm{n}^{\circ}$ 8.884/94 revogada pela Lei 12.529 de 30 de novembro de $2011^{17}$, nesse sentido entendeu a $\mathrm{SDE}^{18}$ :

A cláusula de exclusividade adotada pelo Iguatemi tem assim natureza bastante abrangente, vez que proíbe o lojista de instalar mesmo uma loja que não guarde qualquer relação com a presente no Iguatemi e que se destine a um público completamente distinto nos shoppings especificados. [...]

Com isso, a cláusula em comento é clara ao excluir os shoppings atingidos pela mesma não somente daquela loja ou grife presente no Iguatemi, mas do próprio lojista e de todos os seus sócios enquanto potenciais interessados em espaços de locação comercial. Há que se atentar, ainda, para o peso da cláusula de exclusividade e a punição que nela se estabelece para o seu descumprimento. O lojista que a desobedecer pagará multa proporcional ao seu faturamento no outro shopping, ou seja, quanto maior o seu sucesso no outro empreendimento, maior a penalidade sofrida. Além disso, para pagar a multa ele estará obrigado a abrir a sua contabilidade a alguém (o shopping Iguatemi) que não está envolvido com o empreendimento, o que se afigura como, claramente, abusivo. [...]

Um outro fator que agrava os efeitos prejudiciais à concorrência da cláusula de exclusividade em discussão diz respeito à tendência, apontada neste parecer, das restrições contratuais recaírem sobre áreas dentro dos shoppings valorizadas pelos consumidores de alto poder aquisitivo (moda, livrarias, joalherias, saúde \& beleza).

17 A Lei $n^{\circ} 8.884$ de 1994 foi revogada pela Lei ${ }^{\circ} 12.529$ de 30 de novembro de 2011, que estrutura o sistema brasileiro de defesa da concorrência e dispõe sobre as infrações contra a ordem econômica. O rol de infrações contra a ordem econômica está atualmente contido no art. 36, incisos I a IV, e $\S 3^{\circ}$ do art. 36, incisos de I a XIX. 18 BRASIL. CONSELHO ADMINISTRATIVO DE DEFESA ECONÔMICA. Processo Administrativo $\mathrm{n}^{\circ}$ 08012.009991/1998-82. 17/05/2001. Parecer da Secretaria de direito econômico. Disponível em <http://www.cade.gov.br/temp/D_D000000054111653.pdf>. Acesso em 31 de julho de 2015. 
Por conseguinte, em 03 de maio de 2014, o plenário do CADE proferiu acórdão relativo ao processo administrativo $n^{\circ}$ 08012.009991/1998-82, entendendo pela procedência da representação, e condenando o Condomínio do Shopping Center Iguatemi ao pagamento de multa, pela infração à ordem econômica prevista no art. 20, incisos I, II e IV c/c art. 21, incisos IV e V da Lei 8.884 de 1994, atualmente revogada, conforme entendimento do plenário $^{19}$ :

PROCESSO ADMINISTRATIVO. CONDUTA: IMPOSIÇÃO DE CLÁUSULA DE EXCLUSIVIDADE NOS CONTRATOS DE LOCAÇÃO DO SHOPPING CENTER IGUATEMI, NOS QUAIS OS LOJISTAS FICARIAM IMPEDIDOS DE INSTALAR-SE EM DETERMINADOS SHOPPING CENTERS DA CIDADE DE SÃO PAULO. Fixação de mercado relevante em Processos Administrativos para apuração de infração contra a ordem econômica: necessidade de se levar em consideração os efeitos da conduta. Mercado relevante fixado: shopping centers de alto padrão nas regiões da Zona Oeste, norte da Zona Sul e oeste da Zona Central da Cidade de São Paulo. Poder de mercado: inferido a partir do caráter diferenciado do Shopping Center Iguatemi, de sua capacidade de impor preço de locação superior aos demais e de sua parcela de participação no mercado relevante. Efeitos anticoncorrenciais da cláusula de exclusividade caracterizados. Afastada a alegação de razoabilidade da restrição da concorrência. Infração à ordem econômica caracterizada, segundo o art. 20, incisos I, II e IV c/c art. 21 incisos IV e V da Lei 8.884/94. Aplicação de multa equivalente a $1 \%$ do faturamento bruto do Shopping Center Iguatemi no ano de 1997, excluídos os impostos e multa equivalente a $1 \%$ do faturamento bruto do Shopping Centers Reunidos do Brasil Ltda., obtido com a administração do Condomínio Shopping Center Iguatemi da cidade de São Paulo. Observância do disposto no art. 11 da Lei ${ }^{\circ} 9.021 / 95$. Determinação de imediata cessação da conduta infrativa, retirando-se a cláusula de exclusividade dos contratos que a contenham. Outras determinações. ACÓRDÃO Vistos, relatados e discutidos os presentes autos, na conformidade dos votos e das notas eletrônicas, acordam o Presidente e os Conselheiros do Conselho Administrativo de Defesa Econômica -CADE. O Tribunal, por maioria, considerou as Representadas como incursas no art. 20, incisos I e II, bem como no art. 21, incisos IV e V, da Lei $\mathrm{n}^{\circ} 8.884 / 94$, impondo multa, a cada uma, ao valor de $1 \%$ (um por cento) de seus faturamentos brutos anuais, além de outras sanções e determinações, nos termos do voto do Relator. Vencidos o Conselheiro Fernando Marques e o Presidente, que determinavam $\mathrm{o}$ arquivamento do processo. (Grifos nossos).

Corroborando com tal entendimento, em 19 de setembro de 2007 foi publicado o acórdão no processo administrativo no 08012.006636/1997-43 em que o Plenário do CADE reiterou reconheceu novamente a prática da infração prevista no art. 21, IV e V, c/c art. 20, I,

19 Cf. BRASIL. CONSELHO ADMINISTRATIVO DE DEFESA ECONÔMICA. Processo Administrativo $\mathrm{n}^{\circ}$ 08012.009991/1998-82. 17/05/2001. Acórdão do Plenário do CADE. Disponível em < http://www.cade.gov.br/temp/D_D000000054111653.pdf>. Acesso em 31 de julho de 2015. 
da Lei 8.884 de 1994.

Deste modo, o art. $20^{20}$, incisos I, II, IV e o art. $21^{21}$, incisos IV e V da Lei $n^{\circ} 8.884$ de 1994 determinam que são infrações à ordem econômica, dentre outras condutas, os atos que limitem, falseiem ou de qualquer forma prejudiquem a livre concorrência ou livre iniciativa; a dominação de mercado relevante de bens e serviços; o exercício de forma abusiva de posição dominante; a conduta de limitar ou impedir o acesso de novas empresas no mercado; e ainda a criação de dificuldades à constituição, funcionamento ou ao desenvolvimento de empresa concorrente ou de fornecedor adquirente ou financiador de bens ou serviços.

Concluída a análise acerca dos entendimentos pacificados do CADE a respeito da cláusula de exclusividade territorial nos contratos de locação em shoppings centers, que pela ótica do órgão se tratariam de prática anticoncorrencial violadora dos princípios constitucionais da livre iniciativa e livre concorrência, passa-se à análise da perspectiva concorrencial acerca da cláusula de exclusividade territorial nos contratos de franquia.

Conforme analisado no capítulo segundo, a cláusula de territorialidade obriga o franqueado a limitar a comercialização de produtos e prestação de serviços a um determinado local, pré-estabelecido pelas partes, sendo certo que sua praça de atuação é limitada.

Por outro lado, caso as partes acordem com a exclusividade do franqueado no território, o franqueador não poderá nomear outro distribuidor ou franqueado concorrente, naquela praça.

Contudo, o que na prática tem se observado nos contratos de franquia atualmente firmados, é que se tratam de verdadeiros contratos de adesão, uma vez que o franqueado em pouquíssimas situações pode sugerir alterações ao contrato, que reflitam sua realidade, devendo aceitar as condições impostas pelo franqueador, entre elas o território de atuação, ou simplesmente não ingressar no sistema de franquias.

\footnotetext{
${ }^{20}$ BRASIL. Lei $n^{\circ} 8.884$ de 11 de junho de 1994 (Revogada pela Lei no 12.529 de 2011). Art. 20. Constituem infração da ordem econômica, independentemente de culpa, os atos sob qualquer forma manifestados, que tenham por objeto ou possam produzir os seguintes efeitos, ainda que não sejam alcançados: I - limitar, falsear ou de qualquer forma prejudicar a livre concorrência ou a livre iniciativa; II - dominar mercado relevante de bens ou serviços; III - aumentar arbitrariamente os lucros; e IV - exercer de forma abusiva posição dominante.

${ }^{21}$ BRASIL. Lei ${ }^{\circ} 8.884$ de 11 de junho de 1994 (Revogada pela Lei ${ }^{\circ} 12.529$ de 2011). Art. 21. As seguintes condutas, além de outras, na medida em que configurem hipótese prevista no art. 20 e seus incisos, caracterizam infração da ordem econômica; [...] IV - limitar ou impedir o acesso de novas empresas ao mercado; V - criar dificuldades à constituição, ao funcionamento ou ao desenvolvimento de empresa concorrente ou de fornecedor, adquirente ou financiador de bens ou serviços[...].
} 
Os Tribunais de Justiça de diversos Estados, têm adotado o posicionamento de que a cláusula de territorialidade no contrato de franquia possui validade, não representando concorrência desleal, desde que esta esteja formalmente prevista no documento contratual.

A Quarta Câmara Cível do Tribunal de Justiça ${ }^{22}$ do Estado do Rio de Janeiro (TJRJ), reconheceu a validade das cláusulas de territorialidade, para manter a sentença proferida em primeiro grau e condenar a sociedade Flx Consultoria e Franchising Ltda ao pagamento de danos materiais por violação àquelas, conforme acórdão:

EMENTA: FRANQUIA. INADIMPLEMENTO CONTRATUAL. DANOS
EMERGENTES. LUCROS CESSANTES. DESCABIMENTO

Indenização. Rito comum ordinário. "Franchising". 1. Violação contratual que se acha evidenciada pela prova dos autos e com suporte na prova técnica, autorizando a indenização perseguida em danos emergentes. Exegese do art. 1092, parágrafo único do C.C. 2. Procedimentos diversos, como: ausência de preservação da territorialidade, NÃO ATENDIMENTO A EXCLUSIVIDADE, REALIZAÇÃO DE VENDA PORTA-A-PORTA, CONTRATAÇÃO DE CADEIA DE LOJAS "SLOPER", equívocos sucessivos em campanhas publicitarias e hipóteses conexas, que ultimaram por se reconhecer à violação e o direito indenizatório das Autoras. 3. Violação às normas que regulam o contrato de "franchising". 4. DESLEALDADE CARACTERIZADA, QUANDO ALTERA O SISTEMA DE COMERCIALIZAÇÃO (VENDA PORTA-A-PORTA E NEGOCIAÇÃO DOS PRODUTOS COM GRANDE CADEIA DE LOJAS. 5. Reconhecimento dos danos emergentes, na forma da prova técnica. 6. Em sede de lucros cessantes, forçoso é reconhecer que, mesmo no contrato de franchising, não se podendo prever o lucro nos negócios, vez que insertos na mera expectativa do risco contratual, não qualquer motivação legal e/ou fática para se lhe deferir. 7. Não acolhimento da indenização por lucros cessantes. Sendo reconhecida a violação contratual, em razão de inadimplemento da Ré, não há que se falar em multa contratual, motivo pelo qual improcede a pretensão reconvencional. 8. Em se acolhendo o pedido de danos emergentes, mas não o de lucros cessantes, há sucumbência reciproca, na forma do art. 21, do CPC, para a ação, mantendo-se a condenação em reconvenção. 9. Impende o acolhimento do Laudo Pericial, já que deu precisa apreciação à matéria em lide, excluindo-se a parte pertinente aos lucros cessantes, frente à tese de direito supramencionada. 10. Negado provimento a ambos os recursos. (Grifos nossos).

No caso em questão, a Haruê Perfumaria e Cosméticos Ltda e outras franqueadas, ajuizaram ação ordinária em face da Flx Consultoria e Franchising Ltda objetivando indenização, pagamento de danos materiais, lucros cessantes e restituição das taxas cobradas pela franqueadora. Em síntese as autoras celebraram com a ré, individualmente, contratos de franquia pelos quais passaram a utilizar a marca franqueada "Clarity” de artigos cosméticos, e

\footnotetext{
${ }^{22}$ RIO DE JANEIRO. Tribunal de Justiça do Estado do Rio de Janeiro. $4^{\text {a }}$ Câmara Cível. Apelação no 22477/02.
} Rel. Des. Reinaldo Pinto Alberto Filho, J: 11/02/2003, DJ: 12/06/2003. 
alegaram violação contratual, dentre outros motivos pois o contrato previa a exclusividade territorial das franqueadas, que foi brutalmente descumprida com a revenda dos produtos em lojas de departamento ("revenda sloper") e pela venda direta dos produtos por revendedores porta-a-porta. Neste sentido, entendeu o Tribunal de Justiça do Estado do Rio de Janeiro ${ }^{23}$ :

O primeiro e principal ponto de se reconhecer, à evidência, a violação contratual por parte da ré é quanto a indispensável necessidade da franqueadora ter preservado a territorialidade e exclusividade das autoras, mormente quando vários gastos e investimentos ocorreram pelas suplicantes para fins de execução do contrato, padronização de pontos de vendas e o mais conexo, como apontado no vestibular.

Restou incontroverso, tanto que nem a ré nega tais fatos, que, mesmo havendo contrato com as autoras, ultimou por concretizar vendas porta-aporta, além de autorizar a negociação de seus produtos pela cadeia de lojas sloper.

Em caso similar, o Tribunal de Justiça do Estado de Minas Gerais ${ }^{24}$ corroborou com tal opinião através do Acórdão na Apelação Cível $\mathrm{n}^{\circ}$ 1.0024.01.586811-0/001 que negou provimento ao recurso do franqueado, entre outros motivos pela alegada violação à exclusividade territorial, que não foi estabelecida no contrato, e, portanto, não garante tal obrigação à franqueadora.

EMENTA: APELAÇÃO CÍVEL. RESCISÃO DE CONTRATO DE FRANQUIA. RESSARCIMENTO DE PREJUÍZOS. AUSÊNCIA DE DEMONSTRAÇÃO DE CULPA DA FRANQUEADORA. IMPERÍCIA E INÉRCIA DA FRANQUEADA NA ADMINISTRAÇÃO DA EMPRESA. IMPOSSIBILIDADE. Não há falar em culpa da franqueadora pelo insucesso da franqueada e consequentes prejuízos seus, se a prova dos autos demonstrou imperícia e inércia na administração da franquia, bem como o descumprimento de cláusulas contratuais por parte desta.

APELAÇÃO CÍVEL N 1.0024.01.586811-0/001 - COMARCA DE BELO HORIZONTE - APELANTE (S): ATT ATUANTE TREINAMENTOS TELECOMUNICACOES LTDA - APTE (S) ADESIV: MAXITEL S/A APELADO (A) (S): OS MESMOS - RELATOR: EXMO. SR. DES. LUCIANO PINTO. ACÓRDÃO. Vistos etc., acorda, em Turma, a $17^{\mathrm{a}}$ CÂMARA CÍVEL do Tribunal de Justiça do Estado de Minas Gerais, incorporando neste o relatório de fls. na conformidade da ata dos julgamentos e das notas taquigráficas, à unanimidade de votos, EM NEGAR PROVIMENTO À APELAÇÃO PRINCIPAL E DAR PROVIMENTO À APELAÇÃO ADESIVA.

[...] Adiante, também não dou razão à apelante quando assinala que teria havido concorrência desleal com o aval da própria apelada. Em primeiro

${ }^{23}$ Cf. a respeito: RIO DE JANEIRO. Tribunal de Justiça do Estado do Rio de Janeiro. $4^{\text {a }}$ Câmara Cível. Apelação no 22477/02. Rel. Des. Reinaldo Pinto Alberto Filho, J: 11/02/2003, DJ: 12/06/2003.

24 MINAS GERAIS. Tribunal de Justiça do Estado de Minas Gerais. $17^{\mathrm{a}}$ Câmara Cível. Apelação $\mathrm{n}^{\circ}$ 1.0024.01.586811-0/001. Rel. Des. Luciano Pinto, J: 23/03/2006, DJ: 20/04/2006. 
lugar, a alegada exclusividade territorial não restou provada nos autos. O contrato firmado pelas partes não estabeleceu esse direito à fraqueada e, especificamente em relação aos dealers, bem de ver que o contrato em tela foi firmado em 31/05/1999 (f.111/130), e o dos dealers foi em 20/04/1999 (conforme laudo pericial à f. 412). Assim, não vislumbro a alegada concorrência desleal nem qualquer omissão lesiva aos negócios da apelante, haja vista que a apelada não se colocou impedida de encetar outros negócios em razão do contrato de dealers, ainda que a atuação destes se desse na mesma região. [...]

Apesar de o CADE não ter enfrentado diretamente a questão da viabilidade da cláusula de exclusividade territorial do contrato de franquia, o órgão já firmou o posicionamento em diversos processos administrativos de que a franquia empresarial não viola o direito antitruste, mas pelo contrário estimula a concorrência, conforme entendimento da $\mathrm{SDE}^{25}$ :

No tocante aos efeitos associados à utilização de acordos verticais entre empresas, destaca-se a orientação da autoridade de defesa da concorrência da União Européia, no sentido de que, apesar de certas restrições verticais implicarem efeitos negativos ao mercado, tais como: (i) exclusão de outros fornecedores ou de outros compradores através do aumento das barreiras à entrada; (ii) redução da concorrência intermarcas entre as empresas que operam em um mercado; e (iii) redução da concorrência intramarca entre os distribuidores da mesma marca, o fato é que tais restrições frequentemente produzem efeitos positivos ao mercado, em especial promovendo a concorrência, e melhorando a qualidade de produtos e serviços.

De fato é possível imaginar diversos efeitos positivos associados à utilização de acordos verticais, tais como (i) a redução de custos na distribuição, viabilizando economias de escala e escopo e o aumento da competição intermarcas; (ii) impedimento da atuação de free riders; (iii) ao impor uma certa uniformidade e normas de qualidade aos seus distribuidores, o agente pode promover uma boa imagem da marca e aumentar o interesse do consumidor; e (iv) aumento da possibilidade de entrada em determinado mercado, em razão de permitir o retorno do investimento efetuado.

Deste modo, o entendimento firmado pelo CADE em relação à cláusula de territorialidade nos contratos de locação em shopping centers determinando a condenação destes pela prática de infrações à ordem econômica, à livre concorrência e livre iniciativa, se contrapõe ao entendimento do órgão acerca da cláusula de exclusividade territorial nos contratos de franquia, que segundo o CADE, é inerente ao contrato e estimula a concorrência através de redução de custos de distribuição e aumento do consumo. Desta forma entendeu a

\footnotetext{
${ }^{25}$ BRASIL. Conselho Administrativo de Defesa Econômica. Processo Administrativo no 08012.009912/2005-32. 13/11/2001. Parecer da Secretaria de direito econômico. Disponível em < http://www.cade.gov.br/temp/D_D000000399301010.pdf>. Acesso em 07 de agosto de 2015.
} 
$\mathrm{SDE}^{26}:$

Finalmente, entende-se que a divisão de mercados - geográfica ou por clientese a fixação de preços a serem praticados pelos franqueados, são características inerentes ao contrato de franquias, e subjazem ao contrato que foi firmado entre a DEL VALLE e suas franqueadas. Logo, não é de se admitir a alegação da Representante de tratar-se de conduta anticoncorrencial praticada pela franqueadora.

Além disso, os fundamentos utilizados pelo CADE para a análise do contrato de locação levaram em consideração o mercado relevante de shopping centers, perfil de consumidores, e de que forma o impedimento dos locatários, ou seus sócios abrirem novos estabelecimentos comerciais impactavam o mercado. Deste modo, como visto, ficou constatado pelo CADE que a cláusula de territorialidade nos contratos de locação de shopping centers é uma cláusula abusiva que prejudica a livre iniciativa e a livre concorrência.

Desta forma, não há justificativa para a previsão de tais cláusulas nos contratos de locação de shoppings centers, uma vez que são aplicadas por livre arbítrio dos locadores e apenas cerceiam a livre iniciativa dos comerciantes que não poderiam abrir novas lojas em locais vizinhos, ou mesmo outros shoppings, portanto restringindo a concorrência, e elevando o poder de mercado do locador e seus preços, pela procura dos consumidores.

Sob outra perspectiva, o entendimento do CADE acerca da cláusula de territorialidade nos contratos de franquias, apesar desta problemática não ter sido enfrentada diretamente pelo órgão, é no sentido de que aquela é inerente à franquia empresarial, sendo certo que sua aplicação é justificada e não viola a livre iniciativa e a livre concorrência.

Ademais, há que se falar os contratos de franquia possuem características específicas, entre elas a licença de uso da marca do franqueador, que configura um grande risco para este uma vez que a marca é o bem de maior valor para um sistema de franquias, e uma franquia mal administrada poderá diminuir o valor desta marca, afetar a reputação da rede de franquias, e, por conseguinte, não apenas o franqueador seria prejudicado, mas todos os franqueados.

Por este motivo, é justificável à franquia a imposição de certas regras aos franqueados, bem como uma divisão geográfica clara para sua administração, visando assim a sustentabilidade da rede de franquias.

26 Cf. BRASIL. Conselho Administrativo de Defesa Econômica. Processo Administrativo $\mathrm{n}^{\circ}$ 08012.009912/2005-32. 13/11/2001. Parecer da Secretaria de direito econômico. Disponível em < http://www.cade.gov.br/temp/D_D000000399301010.pdf>. Acesso em 07 de agosto de 2015. 


\section{CONCLUSÃO}

Pelo exposto, franquia empresarial trata-se de um sistema de distribuição bastante vantajoso pelo qual um franqueador cede ao franqueado o direito de uso de marca ou patente, associado ao direito de comercialização exclusiva ou semiexclusiva de produtos ou serviços e, eventualmente, também ao direito de uso de tecnologia de implantação e administração de negócio ou sistema operacional desenvolvidos ou detidos pelo franqueador, mediante remuneração direta ou indireta, sem que no entanto fique caracterizado o vínculo empregatício.

A cláusula de territorialidade é fundamental ao contrato de franquia, uma vez que estabelece a praça de atuação desta, ou seja, delimita o território em que o franqueado poderá comercializar seus produtos, ou prestar serviços.

O território influencia diretamente na rentabilidade da franquia, sendo necessária a análise mercadológica, estrutural e de perfil de consumo local pelos possíveis franqueados, e pelo franqueador, antes da formalização do contrato.

Considerando a relevância do território para implantação da franquia, o legislador determinou na Lei $\mathrm{n}^{\circ} 8.955$ de 1994 que a circular de oferta de franquia, obrigatoriamente, deve informar se haverá exclusividade ou preferência no território, e se existe a possibilidade do franqueado realizar vendas ou prestar serviços fora de seu território, ou realizar exportações.

Apesar de o CADE não ter enfrentado diretamente o aspecto concorrencial da cláusula de territorialidade nos contratos de franquia, esta cláusula já foi objeto de julgamento em relação aos contratos de locação em shoppings centers, em que o CADE condenou o Condomínio do Shopping Center Iguatemi pela prática de conduta anticoncorrencial que viola a livre iniciativa e a livre concorrência.

Por outro lado, o CADE manifestou em diversos julgados o entendimento de que a cláusula de territorialidade é inerente à franquia empresarial, e esta não representa um instituto violador da concorrência, considerando que este sistema diminui os custos de distribuição, viabilizando economias de escala e escopo e o aumento da competição intermarcas; estabelece uma padronização e regras qualidade aos seus franqueados, promovendo uma imagem saudável da marca e aumentando o interesse do consumidor; e 
possibilita a entrada de agentes em determinado mercado, em razão de permitir o retorno do investimento efetuado.

Outrossim, conclui-se que existe uma justificativa sustentável para a imposição de certas cláusulas ao contrato de franquias, uma vez que este pressupõe a licença de uso de marca ao franqueado.

A marca do franqueador é seu bem mais valioso, e a má administração de um franqueado pode afetar a reputação daquele e de toda a rede de franquias, diminuindo o valor da marca. Sob esta perspectiva, a cláusula de territorialidade não seria considerada uma prática anticoncorrencial, mas um instrumento de gestão global do franqueador.

Contudo, a falta de posicionamento claro dos Tribunais Superiores e do CADE a respeito da cláusula de territorialidade nos contratos de franquia, prejudica a análise sob a ótica do direito concorrencial. Apenas quando estes órgãos se manifestarem diretamente sobre a referida cláusula, poder-se-á esclarecer definitivamente a questão.

\section{REFERÊNCIAS}

BARROSO, Luiz Felizardo. Franchising e Direito. Rio de Janeiro. Lumen Juris. 2002.

. Representação comercial x franchising. As vantagens da franquia empresarial In Revista da EMERJ, v. 13, nº50, Rio de Janeiro, 2010.

BRASIL. CONSELHO ADMINISTRATIVO DE DEFESA ECONÔMICA. Processo Administrativo $\mathrm{n}^{\mathrm{o}}$ 08012.006636/1997-43. 07/04/2005. Parecer da Secretaria de direito econômico. Disponível em < http://www.cade.gov.br/temp/D_D000000281181641.pdf>. Acesso em 31 de julho de 2015 às 11:08.

. Processo Administrativo $\mathrm{n}^{\mathrm{o}}$ 08012.009991/1998-82. 17/05/2001. Parecer da

Secretaria de direito econômico. Disponível em
<http://www.cade.gov.br/temp/D_D000000054111653.pdf>. Acesso em 31 de julho de 2015.

Processo Administrativo $\mathrm{n}^{\mathrm{o}}$ 08012.009912/2005-32. 13/11/2001. Parecer da Secretaria de direito econômico. Disponível em < http://www.cade.gov.br/temp/D_D000000399301010.pdf >. Acesso em 07 de agosto de 2015. 
COELHO, Fábio Ulhôa. Curso de Direito Comercial. Volume 1. São Paulo. Editora Saraiva. 2012.

DINIZ, Maria Helena. Tratado teórico e prático dos Contratos. São Paulo. Editora Saraiva. 2003.

HOLLOWELL, Ken. The History of Franchising. Artigo disponível em: http://www.evancarmichael.com/Franchises/666/THE-HISTORY-OF-

FRANCHISING.html>. Acesso em 28 de maio de 2015.

MARTINS. Fran. Curso de Direito Comercial. 37ª Edição. Rio de Janeiro. Editora Gen, 2014.

MILITELLI, Marco. Obrigações legais da Lei de Franchising 8.955/94. Disponível em http://www.portaldofranchising.com.br/artigos-sobre-franchising/como-transformar-seunegocio-em-uma-franquia/obrigacoes-legais-da-lei-de-franchising-895594. Acesso em 20 de julho de 2015.

PIRES, Marcia. Responsabilidades e obrigações entre franqueado e franqueador. Disponível em:http://www.portaldofranchising.com.br/artigos-sobre-franchising/o-que-e-franchising/ responsabilidades-e-obrigacoes-entre-franqueado-e-franqueador. Acesso em 20 de julho de 2015.

ROCCA, Marcus Eduardo. Os Clusters Comerciais e as preferências dos consumidores paulistanos (DISSERTAÇÃO). São Paulo. Universidade Paulista, 2012.

ROSA, Alberto Lopes da. A evolução do contrato de franquia empresarial no direito brasileiro e soluções para um desequilíbrio congênito. Disponível em: http://www.publicadireito.com.br/artigos/?cod=f8e59f4b2fe7c570. Acesso em 20 de julho de 2007.

TRICHES, Maria Isabel; MEURER, Dayci; ANDRADE, Jéssica Teixeira de; TONETE, Vanessa Alves; FOLLMAN, Neimar. Fatores de localização determinantes para o varejo. Anais do Congresso Internacional de Administração, Paraná, 2014. Disponível em: http://www.admpg.com.br/2014/selecionados.php. Acesso em 28 de Julho de 2015. 
TRIBUNAL DE JUSTIÇA DO ESTADO DE MINAS GERAIS. 17ª Câmara Cível. Apelação no 1.0024.01.586811-0/001. Rel. Des. Luciano Pinto, J: 23/03/2006, DJ: 20/04/2006.

TRIBUNAL DE JUSTIÇA DO ESTADO DO RIO DE JANEIRO. $4^{\text {a }}$ Câmara Cível. Apelação n 22477/02. Rel. Des. Reinaldo Pinto Alberto Filho, J: 11/02/2003, DJ: 12/06/2003. 